\title{
Progression of atrophy of the corpus callosum with deterioration of cerebral cortical oxygen metabolism after carotid artery occlusion: a follow up study with MRI and PET
}

\author{
Hiroshi Yamauchi, Marco Pagani, Hidenao Fukuyama, Yasuomi Ouchi, \\ Yasuhiro Nagahama, Shigeru Matsuzaki, Jun Kimura, Yoshiharu Yonekura, Junji Konishi
}

M Pagani

Correspondence to:

Dr Hidenao Fukuyama,

Department of Neurology,

Faculty of Medicine, Kyoto

University, 54 Shogoin

Kawahara-cho, Sakyo-ku,

Kyoto 606, Japan.

Received 18 January 1995

and in revised form

2 February 1995

Accepted 11 May 1995

$(\mp$ Neurol Neurosurg Psychiatry 1995;59:420-426)

Keywords: corpus callosum; carotid artery disease; magnetic resonance imaging

Previous investigations have shown the natural history of occlusion of the internal carotid

\begin{abstract}
Department of Neurology

H Yamauchi

H Fukuyama

Y Ouchi

Y Nagahama

S Matsuzaki

Department of Brain Pathophysiology

Y Yonekura

Department of

Radiology and Nuclear

Medicine, Faculty of

Medicine, Kyoto

University, Kyoto,

Japan

M Pagani

J Konishi

Japan Foundation for

Aging and Health

H Yamauchi

Institute of

Experimental

Medicine, CNR,

Rome, Italy

Abstract

In cerebrovascular disease, progression of brain atrophy may reflect an increase in ischaemic changes. The purpose of this study was to determine whether atrophy of the corpus callosum progresses in association with a deterioration in cerebral cortical oxygen metabolism after occlusion of the carotid artery. Magnetic resonance imaging and PET were used to serially evaluate six patients with occlusion of the unilateral internal carotid artery at intervals ranging from 12 to 50 months. One patient had no symptoms, one had a transient ischaemic attack, and four had a minor stroke. All patients had presented at most only subcortical lesions at the first evaluation. During follow up, no patient showed extension of subcortical lesions or recurrent stroke. The initial total callosal area:skull area ratio for the patients was significantly less than that for 14 age matched normal control subjects. The yearly decrease of callosal size in the patients, which differed significantly from zero and exceeded that in the controls, was significantly correlated with the deterioration in mean cerebral cortical oxygen metabolism. Three of the four patients who showed significant progression of callosal atrophy presented deterioration in haemodynamic states as well. It is concluded that in some patients atrophy of the corpus callosum progresses after occlusion of the carotid artery even in the absence of any overt episode of stroke, and that this atrophy is associated with deterioration in cerebral cortical oxygen metabolism. An increase in cerebral morphological changes with deterioration in cerebral metabolism related to ischaemia may occur after occlusion of the carotid artery, even in the absence of symptoms.
\end{abstract}

artery in relation to the risk of death and stroke. ${ }^{1}$ The types of ischaemic changes that occur and the course of the process of changes in brain metabolism after internal carotid artery occlusion remain unclear. To our knowledge, no serial study of the relation between the morphological and metabolic changes after internal carotid artery occlusion has been conducted with both MRI and PET.

After internal carotid artery occlusion, low perfusion or microembolism can produce cerebral ischaemic changes. ${ }^{23}$ Although most of these events are clinically apparent or are detectable as infarction on CT or MRI, some of them may produce only subtle subjective symptoms and may be detected only as emergence of brain atrophy with metabolic depression. Computed tomography studies in internal carotid artery occlusive disease have disclosed only hemiatrophy in some patients. ${ }^{45}$ Also, a recent cross sectional study with MRI and PET showed that atrophy of the corpus callosum occurs in association with decreased cerebral cortical oxygen metabolism in internal carotid artery occlusive disease without apparent infarction on CT. ${ }^{6}$ The largest fraction of neurons projecting into the corpus callosum are the large pyramidal cells in layer $3,{ }^{7}$ which is one of the groups of cortical neurons most vulnerable to ischaemia. ${ }^{8}$ Therefore, callosal atrophy may result from cortical ischaemic changes that are not detectable as infarction by $\mathrm{CT}$, and its progression after internal carotid artery occlusion may reflect the occurrence of new ischaemic changes with deterioration in cerebral cortical metabolism.

Our purpose in this study was to find whether atrophy of the corpus callosum progresses after internal carotid artery occlusion and, if so, whether this atrophy is associated with a deterioration in cerebral cortical oxygen metabolism. We serially studied six patients with internal carotid artery occlusion by MRI and PET, and quantitatively evaluated the relation between the changes in callosal size and those in cortical oxygen metabolism.

\section{Methods}

SUBJECTS

Six right handed patients (three men and three women) with unilateral internal carotid 
artery occlusion, aged 57-73 (mean (SD) 62 (6)) years, were studied by MRI and PET at the first evaluation. They were consecutive patients whom we could follow up for more than one year and who underwent second MRI and PET evaluation between 1993 and 1994. All patients were followed up with medical treatment including antiplatelet treatment. The interval between the studies ranged from 12 to 50 (mean (SD) 25 (13)) months. The internal carotid artery occlusion was diagnosed by conventional angiography. One patient had no symptoms, one had a transient ischaemic attack, and four had minor strokes at the time of the first evaluation. All symptoms were related to the affected carotid distribution. In the asymptomatic patient, internal carotid artery occlusion was suspected because of the finding of flow void loss at MRI examination performed because of hoarseness. In all of the other patients, punctate or patchy high intensity areas were found in the affected cerebral white matter on T2 weighted MRI. A lesser degree of abnormality was found on the nonaffected side in three patients. Most of these abnormalities were undetectable on $\mathrm{T} 1$ weighted MRI, which showed at most only minor subcortical abnormalities in the affected middle cerebral artery territory. During follow up, no patient had new symptoms. Table 1 shows the clinical and neuroradiological data in each patient.

In all patients, the first MRI studies were performed at least two months after the latest ischaemic event. The PET studies were conducted within one week before or after the MRI studies at both the initial and follow up studies. All patients were in stable condition at the time of the second studies. All subjects gave informed consent to undergo the MRI and PET studies.

We also studied 14 right handed control subjects (eight men and six women) (mean (SD) age at first evaluation 58 (6) years) twice with MRI. The interval between the studies ranged from 12 to 43 months (mean (SD) 17 (9) months). They were normal subjects who underwent a routine neurological examination including MRI for the screening of asymptomatic brain disease. None of these subjects showed any cerebral symptoms, abnormal neurological findings, or specific neurological diseases. In all of the control subjects, punctate high intensity areas of various degrees were noted in the bilateral subcortical white matter on T2 weighted MRI images without corresponding abnormality on $\mathrm{T} 1$ weighted images. Seven of them had hypertension, and three others had diabetes mellitus.

\section{MAGNETIC RESONANCE IMAGING}

The MRI was performed with a Signa unit (General Electric, Milwaukee, MI, USA) operating at a field strength of 1.5 Tesla. The T1 weighted sagittal images were taken with a spin echo pulse sequence (repetition time: $400 \mathrm{~ms}$; echo time: $20 \mathrm{~ms}$ ). Axial T2 weighted images were also taken with spin echo pulse sequences (repetition time: 3000 $\mathrm{ms}$; echo time: $80 \mathrm{~ms}$ ). The slice thickness was $3 \mathrm{~mm}$ for both types of images. Sections were acquired contiguously in the sagittal plane and at an intersection gap of $1.5 \mathrm{~mm}$ in the axial plane.

In the measurement of the extent of atrophy of the corpus callosum, midsagittal images were quantitatively analysed with a computer assisted image analyser (FDM98-1; Photron, Tokyo, Japan) and a personal computer (PC-9801; Nihon Electric, Tokyo, Japan), as previously described. ${ }^{69}$ The software for image analysis was programmed by a member of our research team. Each MRI was recorded with a video camera and digitised by the image analyser with a $256 \times 256$ data matrix and a 64 step grey scale. The number of pixels with signal intensities corresponding to the predetermined level set for the region of interest was then counted. The total area of the corpus callosum was measured, and the absolute values were calculated from a reference scale of MRIs. People with a small skull size may have a small corpus callosum. ${ }^{10}$ Thus we measured the area of the midline internal skull surface (along the inner table, foramen magnum, clivus, sellar diaphragm, and jugum sphenoidale) on the same midsagittal images, and calculated the total callosal area:skull area ratio to control for variation in skull size. ${ }^{10}$ Although to this end a callosal volume:skull volume ratio is preferable, we chose the area ratio as the measurements are easier. All measurements were performed by one investigator

Table 1 Clinical and radiographic data for the six patients with occlusion of the internal carotid artery

\begin{tabular}{|c|c|c|c|c|c|c|}
\hline $\begin{array}{l}\text { Patient No/ } \\
\text { age/sex }\end{array}$ & $\begin{array}{l}\text { Interval } \\
\text { between } \\
\text { scans } \\
\text { (months) }\end{array}$ & Complications & $\begin{array}{l}\text { Clinical features at the } \\
\text { first scan }{ }^{\star}\end{array}$ & $\begin{array}{l}\text { Angiography } \\
\text { (collateral) }\end{array}$ & $\begin{array}{l}\text { Infarct site and size } \\
(\mathrm{mm} \times \mathrm{mm}) \\
\text { on } T 1 \text { weighted } M R I \\
\text { at the first scan }\end{array}$ & $\begin{array}{l}\text { Neurological outcome } \\
\text { at the second scan } \\
\text { (residual signs) }\end{array}$ \\
\hline $1 / 59 / \mathrm{F}$ & 15 & MI & No symptom & R ICA occlusion & None & No change (none) \\
\hline $2 / 59 / M$ & 24 & $\begin{array}{l}\mathrm{HT} \\
\mathrm{DM}\end{array}$ & $\begin{array}{l}\text { Transient }(\mathrm{L}) \text { visual disturbance } \\
(5 \text { months })\end{array}$ & $\begin{array}{l}\text { L ICA occlusion } \\
\text { (leptomeningeal) }\end{array}$ & $\begin{array}{l}\text { L frontal subcortex } \\
(7 \times 10)\end{array}$ & No change (none) \\
\hline $3 / 67 / M$ & 12 & None & $\begin{array}{l}\text { Minor (R) hemisphere stroke } \\
(5 \text { months })\end{array}$ & $\begin{array}{l}\text { R ICA occlusion } \\
\text { (A com) }\end{array}$ & $\begin{array}{l}R \text { corona radiata } \\
(8 \times 20)\end{array}$ & $\begin{array}{l}\text { Good recovery } \\
\text { (slight dysarthria) }\end{array}$ \\
\hline $4 / 73 / M$ & 22 & None & $\begin{array}{l}\text { Minor (R) hemisphere stroke } \\
(5 \text { months) }\end{array}$ & $\begin{array}{l}\mathrm{R} \text { ICA occlusion } \\
\text { (A com) }\end{array}$ & $\begin{array}{l}\mathbf{R} \text { corona radiata } \\
(5 \times 10)\end{array}$ & $\begin{array}{l}\text { Good recovery } \\
\text { (L upper limb drift) }\end{array}$ \\
\hline $5 / 58 / F$ & 29 & DM & $\begin{array}{l}\text { Minor (R) hemisphere stroke } \\
\text { (12 months) }\end{array}$ & $\begin{array}{l}\text { R ICA occlusion } \\
\text { (leptomeningeal) }\end{array}$ & $\begin{array}{l}R \text { frontal subcortex } \\
(10 \times 5)\end{array}$ & $\begin{array}{l}\text { Poor recovery } \\
\text { (mild L hemiparesis) }\end{array}$ \\
\hline $6 / 57 / F$ & 50 & $\begin{array}{l}\text { HT } \\
\text { DM }\end{array}$ & $\begin{array}{l}\text { Minor }(L) \text { hemisphere stroke } \\
\text { (6 months) }\end{array}$ & $\begin{array}{l}\text { L ICA occlusion } \\
\text { (A com) }\end{array}$ & $\begin{array}{l}\text { L centrum semiovale } \\
(5 \times 8)\end{array}$ & $\begin{array}{l}\text { Poor recovery } \\
\text { (mild R hemiparesis) }\end{array}$ \\
\hline
\end{tabular}

*The times in parentheses indicate the interval between the onset of each symptom and the initial scan.

MI = Myocardial infarction; HT = hypertension; DM = diabetes mellitus; $\mathrm{L}=$ left; $\mathrm{R}=$ right; $\mathrm{ICA}=$ internal carotid artery; $\mathrm{A}$ com = anterior communicating $\mathrm{MI}=M$ M.
artery. 
who was blinded to the clinical state of the patients. Before this study, the reliability of our procedure within each observer was evaluated in 20 subjects, with and without neurological diseases. There was high reliability in the measurement of the callosal area and the midline internal skull surface area within each observer $(r=0.99, \mathrm{P}<0.0001$ and 0.975, $\mathrm{P}<0.0001$ respectively).

The total change of the corpus callosum area:skull area ratio was calculated by subtracting the ratio obtained at the second scan from that obtained at the first scan, and the yearly change was also calculated by dividing the value by the time interval between scans for comparison between subjects although the corpus callosum area:skull area ratio may not decrease linearly:

Yearly change $=\frac{\text { area ratio }(\text { second })-\text { area ratio }(\text { first })}{\text { time interval between scans }(\text { year })}$

POSITRON EMISSION TOMOGRAPHY

All patients and seven additional normal volunteers (four men and three women; mean (SD) age 51 (16) years) were scanned with a PCT-3600W system (Hitachi Medical, Japan). A detailed description of this PET scanner has been published previously. ${ }^{112}$ This system acquires 15 slices with a centre to centre distance of $7 \mathrm{~mm}$ and a transaxial resolution of $6.5 \mathrm{~mm}$ full width at half maximum (FWHM) at the centre. The slice thickness at the centre is $6.9 \mathrm{~mm}$ FWHM and $5.9 \mathrm{~mm}$ FWHM for in plane and cross plane slices respectively. As part of the scanning procedure but before the PET study, germanium68-gallium-68 transmission scanning was performed for 20 minutes for attenuation correction. The cerebral blood flow (CBF) was measured while the subject continuously inhaled $300 \mathrm{MBq}$ of $\mathrm{CO}^{15} \mathrm{O}$ a minute through a mask, and the measurement of the cerebral metabolic rate of oxygen $\left(\mathrm{CMRO}_{2}\right)$ and oxygen extraction fraction (oEF) was performed during continuous inhalation of $500 \mathrm{MBq}$ of $\mathrm{O}^{15} \mathrm{O}$ a minute. Data were collected for five minutes. A single breath of $1 \cdot 00-1 \cdot 20 \mathrm{GBq}$ of $\mathrm{C}^{15} \mathrm{O}$ was used to measure cerebral blood volume (CBV). We calculated $\mathrm{CBF}, \mathrm{CMRO}_{2}$, and oEF based on the steady state method. ${ }^{13}$ The $\mathrm{CMRO}_{2}$ and oEF were corrected by the CBV. ${ }^{14}$ Functional images were reconstructed as $128 \times 128$ pixels, with each pixel representing an area of $2.0 \times 2.0 \mathrm{~mm}$. The ratio of CBF to $\mathrm{CBV}$ was calculated pixel by pixel as an

Table 2 Physiological data obtained in the patients and controls at the first and second evaluations

\begin{tabular}{|c|c|c|c|}
\hline \multirow[b]{2}{*}{ Variable } & \multicolumn{2}{|l|}{ Patients } & \multirow[b]{2}{*}{ Controls } \\
\hline & First study & Second study & \\
\hline $\begin{array}{l}\text { Packed cell volume } \\
\quad(\%) \\
\mathrm{Haemoglobin}(\mathrm{g} / \mathrm{dl}) \\
\mathrm{PaCO}_{2}(\mathrm{~mm} \mathrm{Hg}) \\
\mathrm{PaO}_{2}(\mathrm{~mm} \mathrm{Hg}) \\
\mathrm{CaO}_{2}(\mathrm{ml} / \mathrm{dl}) \\
\mathrm{MABP}(\mathrm{mm} \mathrm{Hg})\end{array}$ & $\begin{array}{c}39.8(3.7) \\
13.5(1.2) \\
39.5(5.6) \\
84.0(6.5) \\
18.0(1.7) \\
113.5(14.0)\end{array}$ & $\begin{array}{c}39 \cdot 2(2 \cdot 3) \\
13 \cdot 3(0 \cdot 9) \\
40 \cdot 9(4 \cdot 7) \\
85 \cdot 2(9 \cdot 8) \\
17 \cdot 7(1 \cdot 2) \\
128 \cdot 8(19 \cdot 0)\end{array}$ & $\begin{array}{l}39.2(5 \cdot 1) \\
13.2(1 \cdot 7) \\
40.3(2 \cdot 9) \\
94 \cdot 7(10 \cdot 0) \\
18 \cdot 1(2 \cdot 3) \\
101.9(8 \cdot 7)\end{array}$ \\
\hline
\end{tabular}

Values are mean (SD). $\mathrm{CaO}_{2}=$ total oxygen content of arterial blood; MABP = mean arterial blood pressure. indicator of cerebral perfusion reserve. ${ }^{15}$ Table 2 shows the mean physiological data for the patients and controls acquired during the PET study.

In this study, the patients were scanned through tomographic planes parallel to the orbitomeatal line. Each patient's head was positioned by means of a light grid projected on to the forehead, the lines of which were aligned to markings made on the skin with a felt tipped pen. For the follow up studies, care was taken to ensure to the greatest extent possible that the patient was scanned through anatomical planes identical to those in the first PET study. A method ensuring exact repositioning of the patient's head, such as fixation with a customised headholder for each subject, however, was not used. Also, the magnitude of test retest variability over months to years was not studied.

We analysed six tomographic planes 43,50 , $57,64,71$, and $78 \mathrm{~mm}$ above and parallel to the orbitomeatal line, which corresponded to the levels from the basal ganglia and thalamus to the centrum semiovale. The region of interest was placed on the CBF images and the method for CT PET imaging coregistration was not used. Each image was examined by placing 15 to 17 circular regions of interest $12 \mathrm{~mm}$ in diameter over the grey matter of the cortex. According to the atlas prepared by Kretschmann and Weinrich, ${ }^{16}$ the regions of interest in all six images were included in the distribution of the anterior cerebral artery, middle cerebral artery, and posterior cerebral artery, as well as the watershed areas between the anterior and middle cerebral arteries (anterior watershed) and the middle and posterior cerebral arteries (posterior watershed). The mean hemispheric and cerebral values were calculated as the average of the middle cerebral artery, anterior watershed, and posterior watershed region of interest, and each was weighted by region size. ${ }^{17}$

The total changes of the PET variables were calculated by subtracting the values obtained at the second scanning from those obtained at the first scanning, and the yearly change of the mean cerebral cortical oxygen metabolism was calculated by dividing the total change of $\mathrm{CMRO}_{2}$ value by the time interval between scans:

Yearly change $=\frac{\mathrm{CMRO}_{2} \text { value (second) }-\mathrm{CMRO}_{2} \text { value (first) }}{\text { interscan time interval (year) }}$

STATISTICAL ANALYSIS

We compared the total callosal area:skull area ratios of the patients with those of the controls with the Mann-Whitney $U$ test. Statistical significance was accepted at $P<0.05$.

The CBF, $\mathrm{CMRO}_{2}, \mathrm{OEF}, \mathrm{CBV}$, and CBF:CBV values in each hemisphere obtained at the first and second PET studies in the patients were compared with those obtained in the seven normal volunteers with the Mann-Whitney $U$ test when the KruskalWallis one way analysis of variance showed main group effects. Significance in the MannWhitney $U$ test was accepted at a $P$ value of 
less than 0.0125 with Bonferroni's correction for multiple comparisons. We also compared the values obtained at the first and second evaluations with the paired Wilcoxon signed rank test; $P<0.05$ was considered to indicate a significant difference.

We analysed the relation of the yearly change of the corpus callosum area:skull area ratio in the patients to that of mean cerebral $\mathrm{CMRO}_{2}$ values and to the total changes in $\mathrm{CBF}$, oEF, and $\mathrm{CBF}: \mathrm{CBV}$ ratio using

Table 3 Initial callosal area:skull area ratio and yearly change in callosal area:skull area ratio in patients and controls

\begin{tabular}{lll}
\hline & $\begin{array}{l}\text { Initial callosal area: } \\
\text { skull area ratio }\end{array}$ & $\begin{array}{l}\text { Yearly change in } \\
\text { callosal area: } \\
\text { skull area ratio }\end{array}$ \\
\hline Patients & $32.6(10.2) \times 10^{-3 \star}$ & $-1 \cdot 73(1.54) \times 10^{-3 \star}$ \\
Controls & $41.7(4.5) \times 10^{-3}$ & $-0.24(0.22) \times 10^{-3}$ \\
\hline
\end{tabular}

$\star \mathrm{P}<0.05 \mathrm{v}$ controls (Mann-Whitney $U$ test). Values are means (SD).

Figure 1 Example of progression of atrophy of corpus callosum. $T 1$ weighted sagittal images (TR $400 \mathrm{~ms} / T E 20 \mathrm{~ms}$ ) obtained at the first study (top) and 50 months later (bottom) in patient 6. About 20\% reduction in callosal size was noted. The yearly change in callosal area:skull area ratio was $-2.0 \times 10^{-3} / y$.

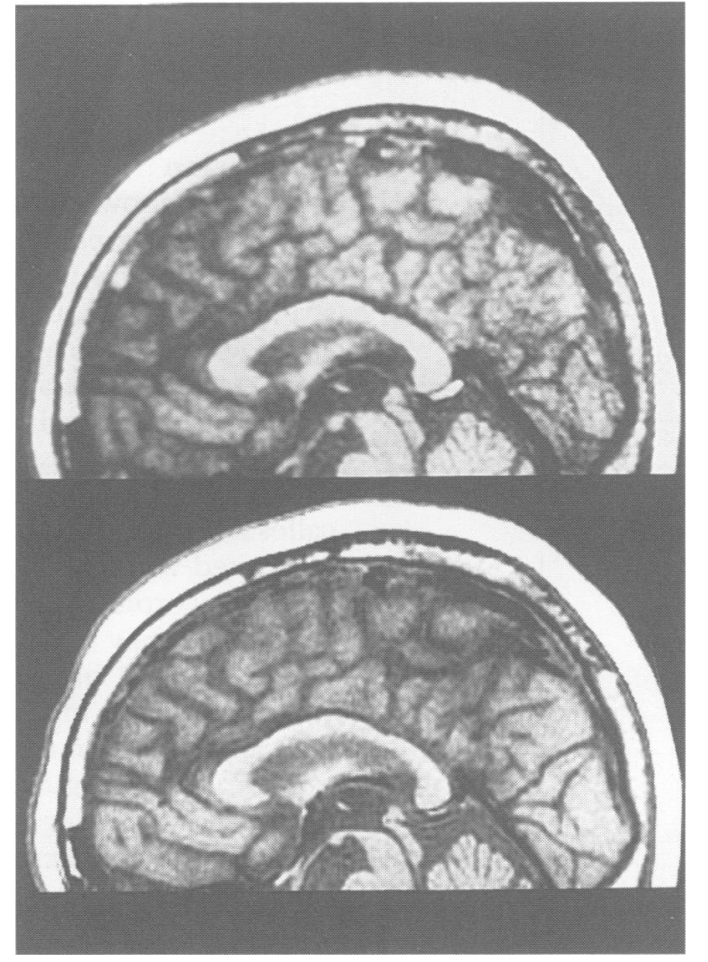

Table 4 Values of regional $C B F, C M R o 2, o E F, C B V$, and the $C B F: C B V$ ratio in the cerebral hemispheres ipsilateral and contralateral to the internal carotid artery occlusion

\begin{tabular}{|c|c|c|c|c|}
\hline \multirow[b]{2}{*}{ Variable } & \multirow[b]{2}{*}{ Hemisphere } & \multicolumn{2}{|l|}{ Patients } & \multirow[b]{2}{*}{ Controls } \\
\hline & & First study & Second study & \\
\hline CBF & Occluded & $36.5(10.3)$ & $30 \cdot 6(7 \cdot 5)^{\star \star}$ & $41 \cdot 0(4 \cdot 3)$ \\
\hline$(\mathrm{ml} / 100 \mathrm{~g} / \mathrm{min})$ & Patent & $42.9(9.5)$ & $37.6(5 \cdot 8)$ & \\
\hline $\mathrm{CMRO}_{2}$ & Occluded & $2.94(0.48)$ & $2.55(0.45)^{\# \prime}$ & $3 \cdot 18(0 \cdot 56)$ \\
\hline $\begin{array}{l}(\mathrm{ml} / \mathrm{g} / \mathrm{min}) \\
\mathrm{OEF}\end{array}$ & Patent & $3.14(0.54)$ & $2 \cdot 85(0 \cdot 20)$ & $40.9(4.0)$ \\
\hline $\begin{array}{l}\text { OEF } \\
(\%)\end{array}$ & $\begin{array}{l}\text { Occluded } \\
\text { Patent }\end{array}$ & $\begin{array}{l}46 \cdot 6(5 \cdot 5) \\
42 \cdot 1(3 \cdot 5)\end{array}$ & $\begin{array}{l}48 \cdot 3(6 \cdot 2)^{\star} \\
43 \cdot 8(4 \cdot 6)\end{array}$ & $40 \cdot 9(4 \cdot 0)$ \\
\hline CBV & Occluded & $4.39(0.87)^{\star}$ & $3.72(0.47)^{*}$ & $3.32(0.41)$ \\
\hline$(\mathrm{ml} / 100 \mathrm{~g})$ & Patent & $3.83(0.85)$ & $3.37(0.71)^{\#}$ & \\
\hline CBF:CBV & Occluded & $8 \cdot 6(2 \cdot 8)^{\star}$ & $8 \cdot 3(1.9)^{\star \star}$ & $12 \cdot 6(2 \cdot 1)$ \\
\hline$(/ \mathrm{min})$ & Patent & $11.9(3.2)$ & $11 \cdot 5(1 \cdot 6)$ & \\
\hline
\end{tabular}

${ }^{\star} \mathrm{P}<0.01$; ${ }^{\star \star} \mathrm{P}<0.005 \mathrm{v}$ controls (Mann-Whitney $U$ test); $\mathrm{P}<0.05 \mathrm{v}$ the first study (paired Wilcoxon signed rank test).

Values are means (SD); CBF = cerebral blood flow; $\mathrm{CMRO}_{2}=$ cerebral metabolic rate of oxygen; $\mathrm{oEF}=$ oxygen extraction fraction; $\mathrm{CBV}=$ cerebral blood volume.
Spearman's correlation analysis; significance was accepted at $\mathrm{P}<0.05$.

\section{Results}

No patient showed extension of subcortical white matter lesions during the follow up period. Two patients (5 and 6 ) developed apparent cortical atrophy in the superior parietal cortex ipsilateral to the internal carotid artery occlusion.

The initial total callosal area:skull area ratio for the patients was significantly decreased compared with that in controls (table 3). Although the yearly decrease of the ratio was significantly greater than zero in both patients and controls (paired Wilcoxon signed rank test), the decrease in the patients exceeded that in controls (table 3 ). Significant progression of callosal atrophy, defined as a value less than $-0.72 \times 10^{-3} /$ year (the lower $95 \%$ confidence limit for the controls), was found in four of the six patients (fig 1).

In the hemisphere ipsilateral to internal carotid artery occlusion the patients had significantly increased $\mathrm{CBV}$ at the first evaluation together with significantly decreased CBF:CBV compared with the controls (table 4). The $\mathrm{CMRO}_{2}$ and $\mathrm{CBV}$ at the second study were significantly decreased compared with those at the first study. The CBF and CBF:CBV showed slight decreases with a

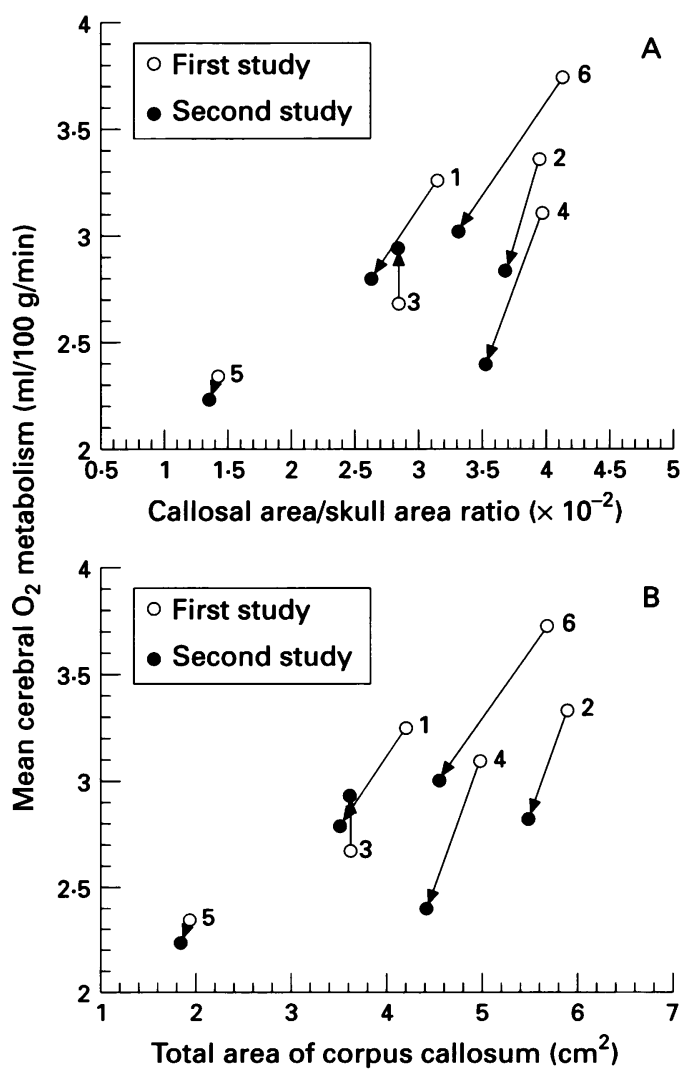

Figure 2 Relation of the mean cerebral cortical oxygen metabolic value to the callosal area:skull area ratio $(A)$ and the callosal area (B) for individual patients at each time point. Numbers correspond to the patient numbers in table 1. 
Figure 3 Relation between the yearly change in callosal area:skull area cerebral cortical oxygen metabolic value in the patients. Numbers correspond to the patient numbers in table 1. ratio and that in mean

$\widehat{\frac{\mathrm{g}}{\mathrm{g}}}$

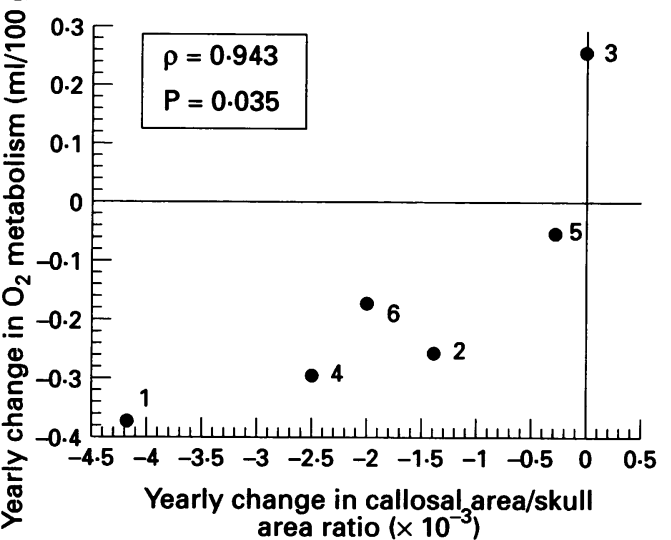

Figure 4 Relation of the yearly change in callosal area:skull area ratio to the total change in mean cerebral cortical blood flow $(A)$, in oxygen extraction fraction $(B)$, and in cerebral blood flow:cerebral blood volume (CBF:CBV) ratio $(C)$ in the patients. The thin vertical line shows the lower $95 \%$ confidence limit for the controls.
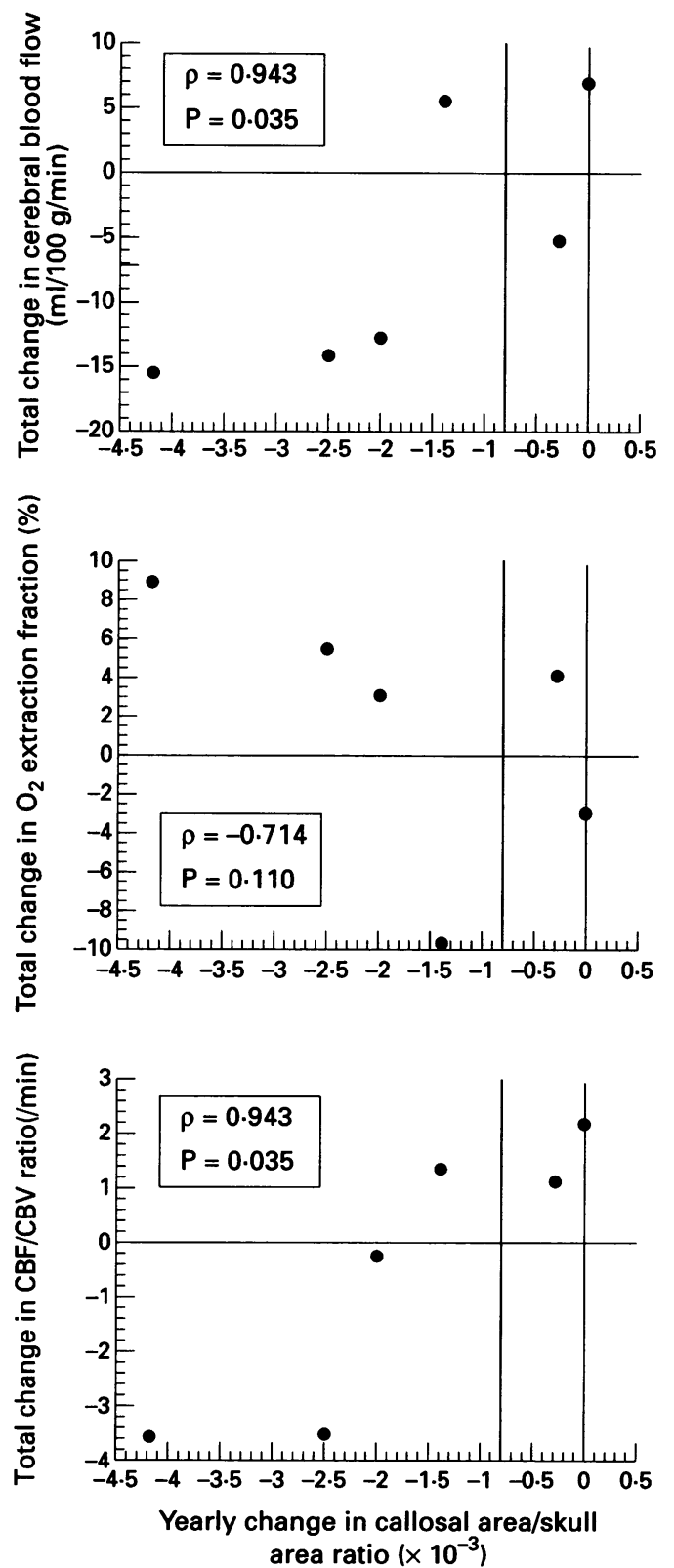

slight oEF increase at the second study, but these changes were not significant. The CBF, oEF, and CBF:CBV at the second evaluation were significantly different from those in controls. In the hemisphere contralateral to the internal carotid artery occlusion, none of the values was significantly different from that in the controls, but the CBV on the contralateral side showed a significant decrease at the second evaluation.

The changes in callosal size and haemodynamic and metabolic variables differed among patients but were mutually correlated. The degree of decrease in the corpus callosum area:skull area ratio was significantly correlated with the degree of deterioration in the mean metabolic value of cerebral cortical oxygen (figs 2 and 3 ). The progression of atrophy of the corpus callosum was related to the deterioration of the patients' haemodynamic state; in three of the four patients who showed significant progression of callosal atrophy, the $\mathrm{CBF}$ and $\mathrm{CBF}: \mathrm{CBV}$ ratio were decreased and the oEF was increased at the second evaluation (fig 4). The progression of callosal atrophy was not related to the initial haemodynamic abnormality or the presence of hypertension or diabetes mellitus.

\section{Discussion}

This study showed that atrophy of the corpus callosum progresses after internal carotid artery occlusion without overt episode of stroke in some patients and that this atrophy is associated with a deterioration in cerebral cortical oxygen metabolism. Serial MRI measurements of callosal area showed significantly more severe decrease in the patients than in age matched normal controls. The degree of callosal atrophy in the patients varied but was correlated with the degree of decline in mean cerebral cortical oxygen metabolism. Also, callosal atrophy was related to the deterioration in cortical haemodynamic state, specifically, a decrease in CBF and CBF:CBV ratio with an increase in oEF. Thus, progression of callosal atrophy may reflect an increase in cerebral morphological changes related to ischaemia and a deterioration in cerebral cortical metabolism after internal carotid artery occlusion.

Cross sectional studies of normal aging have shown that the decrease in callosal size with age, ${ }^{101819}$ and the yearly decrease in callosal area:skull area ratio in men found in one study was $0.27 \times 10^{-3} .{ }^{10}$ This value is comparable with the data in our controls. Thus the yearly decrease in callosal area:skull area ratio in the patients with internal carotid artery occlusion far exceeds that in normal aging. Also, the associated yearly decrease in $\mathrm{CMRO}_{2}$ value $(0.14 \mathrm{ml} / 100 \mathrm{~g} / \mathrm{min})$ was also higher than the reported value attributed to aging $(0.015 \mathrm{ml} / 100 \mathrm{~g} / \mathrm{min}){ }^{20}$ These findings indicate that the progression of callosal atrophy in these patients is a pathological change.

The mechanism of an abnormal progression of callosal atrophy remains to be elucidated. We speculate that the callosal atrophy 
that we found may have resulted from axonal degeneration during the follow up period due to ischaemic cortical lesions ${ }^{21}$ that were not detectable as infarctions with $\mathrm{MRI},{ }^{6}$ because callosal atrophy was associated with a decrease in cortical CMRo. ${ }^{2}$ The CBF value of $30 \mathrm{ml} / 100 \mathrm{~g} / \mathrm{min}$ in our patients, which is above the threshold of acute neuronal death, may contradict this hypothesis. Recent evidence suggests that the threshold for the suppression of protein synthesis is near the normal flow rate, and that the thresholds for disturbances of energy metabolism, unit activity, neurotransmitter release, and histological injury all increase with time during permanent vascular occlusion. ${ }^{22}$ Mild but chronic decrease in CBF with submaximal increase in oEF may cause prolonged inhibition of protein synthesis that might result in delayed neuronal death after internal carotid artery occlusion. Moreover, transient systemic haemodynamic disturbance could cause prompt CBF decrease to a level below the threshold for acute neuronal death in internal carotid artery occlusion due to a poor autoregulatory response. ${ }^{23}$ Because ischaemic changes in the region with increased oEF result in normalisation of the $\mathrm{OEF}$, the finding of an increase in oEF from the first to the second study suggests that chronic deterioration of haemodynamic disturbance exceeding reduction in metabolic demand may be important for the progression of callosal atrophy.

Neuronal loss in the absence of infarction has been demonstrated in humans dying after a severe hypotensive or hypoxic episode. ${ }^{8}$ In animal experiments, carotid artery occlusion and haemorrhagic hypotension are found to cause only microscopic ischaemic changes in the cerebral cortex. ${ }^{24}$ In some patients with internal carotid artery occlusive disease, CT studies have disclosed only hemiatrophy, ${ }^{45}$ suggesting cortical ischaemic damage in the absence of apparent infarction. Mild cortical lesions result in only a decrease in the breadth of cortical ribbons. We found apparent enlargement of focal cortical sulci only in our two patients with long intervals between scans. Although the extent of cortical atrophy can be measured, precise measurement is difficult and neuronal loss can be underestimated because of reactive gliosis. Atrophy of the corpus callosum may sensitively reflect the extent of cortical ischaemic damage because of the vulnerability of the cortical layer 3 . Serial studies, in which the variation between subjects in the initial callosal size is controlled for, may allow more precise measurement of changes related to disease.

Another possible mechanism of callosal atrophy might be delayed transneuronal degeneration..$^{25}$ The ischaemic changes in initial internal carotid artery occlusion have resulted in reduced neuronal input to some areas in the brain that in the long term progresses to degeneration of the denervated neurons and thereby to a secondary degeneration of fibres in the corpus callosum as a consequence of the primary cellular loss. One example of this type of degeneration is delayed thalamic atrophy after cerebral infarction in the middle cerebral artery territory. ${ }^{26}$ But it is not clear how brain metabolism changes in the process of transneuronal degeneration.

Some factors other than ischaemic damage may contribute to callosal atrophy in subjects with internal carotid artery occlusion. The corpus callosum could be subject to influences that are not evident from the results of metabolic studies-such as, diet, alcohol intake, or the coexistence of diabetes. Different structures were used for the measurements of atrophy and of metabolism in this study. Thus we cannot exclude the possibility that callosal atrophy and metabolic decline may be two distinct phenomena lacking any causal relation, although the finding that primary callosal lesions do not irreversibly reduce cortical glucose metabolism ${ }^{27}$ supports our interpretation.

In patients with internal carotid artery occlusion, the risk of ischaemic changes may depend on the severity of haemodynamic abnormality. Recent studies have shown that a small subgroup of patients with increased oEF or highly impaired cerebrovascular reactivity at entry is at increased risk of developing a stroke during the follow up period. ${ }^{28-31} \mathrm{~A}$ larger subgroup of patients with less severe haemodynamic abnormality, including those with abnormal CBV:CBF ratio, did not have high risk for early stroke. ${ }^{32}$ In our patients, none of whom had severe haemodynamic abnormality at the first evaluation, the progression of callosal atrophy with metabolic decline was related not to an initial haemodynamic abnormality but to a deterioration in the haemodynamic state. Evaluation of the changes in cerebral haemodynamics and metabolism with serial studies is needed to determine the risk of ischaemic changes in patients without severe haemodynamic abnormality. Haemodynamics and metabolism may change with time after internal carotid artery occlusion.

Little is known about the natural course of change in cerebral haemodynamics in patients with internal carotid artery occlusion. A few serial studies have shown that cerebrovascular reactivity may change with time. ${ }^{33} 34$ Spontaneous improvement of initially impaired cerebrovascular reactivity was reported in most patients with internal carotid artery occlusion, suggesting the development of intracranial collateralisation. ${ }^{34}$ The decrease in $\mathrm{CBV}$ with time in our patients suggests improvement of cerebrovascular reactivity, because the degree of impaired cerebrovascular reactivity is known to be correlated with $\mathrm{CBV}$ values. ${ }^{35}$ This decrease did not accompany an improvement of cerebral haemodynamics but rather a deterioration of cerebral metabolism, which implies that the decrease in CBV resulted from a decrease in metabolic demand rather than from improvement of perfusion due to the development of collaterals. Thus the change in cerebrovascular reactivity must be interpreted with caution in patients with 
progression of metabolic decline or brain atrophy. The improvement of cerebrovascular reactivity may not necessarily indicate good outcome in terms of the cerebral haemodynamics and metabolism in patients with internal carotid artery occlusion.

In conclusion, atrophy of the corpus callosum progresses after internal carotid artery occlusion without overt episode of stroke in some patients, and this atrophy is associated with deterioration in oxygen metabolism in the cerebral cortex. An increase in morphological changes related to ischaemia and deterioration in metabolism may occur after internal carotid artery occlusion, even in the absence of symptoms.

This work was supported by Scientific Research Grants (C05670556, A-04404043) from the Japanese Ministry of Education, Science, and Culture. We thank the staff of the Department of Radiology and Nuclear Medicine, Faculty of Medicine, Kyoto University (Dr Yasuhiro Magata, Dr Koich Ishizu, and Dr Hidehiko Okazawa) for their support and technical help. We also thank Dr Tadashi Ino, Dr Kazuo Nakamura, Dr Yasumasa Yamamoto, and Dr Kaiyo Oiwa for their cooperation.

1 Hankey GJ, Warlow CP. Prognosis of symptomatic carotid artery occlusion. An overview. Cerebrovascular Disease 1991;1:245-56.

2 Barnett HJM. Delayed cerebral ischemic episodes distal to occlusion of major cerebral arteries. Neurology 1978;28: 769-74.

3 Bogousslavsky J, Regli FA. Borderzone infarctions distal to internal carotid artery occlusion: prognostic implications. Ann Neurol 1986;20:346-50.

4 Radu EW, Moseley IF. Carotid artery occlusion and computed tomography: a clinicoradiological study. computed tomography: a

5 Wodarz R. Watershed infarctions and computed tomography: a topographical study in cases with stenosis or occlusion of the carotid artery. Neuroradiology 1980;19: $245-8$.

6 Yamauchi H, Fukuyama H, Nabatame H, Harada K, Kimura J. Callosal atrophy with reduced cortical oxygen metabolism in carotid artery disease. Stroke 1993;24: 88-93.

7 Innocenti GM. General organization of callosal connections in the cerebral cortex. In: Jones EG, Peters A, eds. Cerebral cortex. 5th ed New York: Plenum Press, 1986: 291-353.

8 Graham DI. Hypoxia and vascular disorders. In: Adams $\mathrm{JH}$, Duchen LW, eds. Greenfield's neuropathology. JH, Duchen LW, eds. Greenfield's

9 Nabatame H, Fukuyama H, Akiguchi I, Kameyama M Nabatame $H$, Fukuyama $H$, Akiguchi I, Kameyama $M$, qualitative and quantitative $M R$ analysis of atrophy. qualitative and quantitative $\mathrm{MR}$ analysi

10 Laissy JP, Patrux B, Duchateau C, et al. Midsagittal MR measurement of the corpus callosum in healthy subjects and diseased patients: a prospective survey. $A \mathcal{F} N R A m \mathcal{F}$ Neuroradiol 1993;14:145-154.

11 Mukai T, Senda M, Yonekura Y, et al. System design and performance of a newly developed high resolution PET scanner using double wobbling mode [abstract]. $\mathcal{f} \mathrm{Nucl}$ Med 1988;29:877.

12 Endo $M$, Fukuda $H$, Suhara $T$, et al. Design and performance of PCT-3600W (15-slice type): a whole-body positron emission tomogra f Nucl Med 1991:32 (suppl):1061.
13 Frackowiak RSJ, Lenzi GL, Jones T, Heather JD. Quantitative measurement of regional cerebral blood flow and oxygen metabolism in man using ${ }^{15} \mathrm{O}$ and positron emission tomography: theory, procedure, and normal values. $¥$ Comput Assist Tomogr 1980;4:727-36.

14 Lammertsma AA, Jones T. Correction for the presence of intravascular oxygen-15 in the steady-state technique for measuring regional oxygen extraction ratio in the brain: 1 . Description of the method. 7 Cereb Blood Flow Metab 1983;3:416-24.

15 Gibbs JM, Wise RJS, Leenders KL, Jones T. Evaluation of cerebral perfusion reserve in patients with carotid artery occlusion. Lancet 1984; i:310-4

16 Kretschmann HJ, Weinrich W. Neuroanatomy and cranial computed tomography New York: Thieme Inc, 1986: $70-4$.

17 Yamauchi H, Fukuyama H, Kimura J, Konishi J, Kameyama M. Hemodynamics in internal carotid artery occlusion examined by positron emission tomography. Stroke 1990;21:1400-6.

18 Yoshii F, Duara R. Size of corpus callosum in normal subjects and patients with Alzheimer's disease. Magnetic resonance imaging study. Clin Neurol (Tokyo) 1989;29: 1-7. (In Japanese.)

19 Weis S, Kimbacher M, Wenger E, Neuhold A. Morphometric analysis of the corpus callosum using MR: correlation of measurements with aging in healthy individuals. AfNR Am f Neuroradiol 1993;14:637-45.

20 Leenders KL, Perani A, Lammertsma AA, et al. Cerebral blood flow, blood volume and oxygen utilization. Normal values and effect of age. Brain 1990;113:24-47.

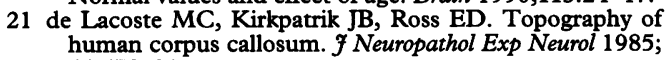
44:578-91.

22 Hossmann K-A. Viability thresholds and the penumbra of focal ischemia. Ann Neurol 1994;36:557-65.

23 Kanno I, Uemura K, Higano S, et al. Oxygen extraction fraction at maximally vasodilated tissue in the ischemic brain estimated from the regional $\mathrm{CO}_{2}$ responsiveness measured by positron emission tomography. $₹$ Cereb Blood Flow Metab 1988;8:227-35.

24 Graham DI, Mendelow AD, Tuor UI, Fitch W. Neuropathologic consequences of internal carotid artery occlusion and hemorrhagic hypotension in baboons. Stroke 1990;21:428-34.

25 Brodal A. Anterograde and retrograde degeneration of nerve cells in the central nervous system. In: Haymaker $\mathrm{W}$, Adams RD, eds. Histology and histopathology of the nervous system. Springfield, IL: Charles C Thomas, 1982:276-362.

26 Tamura A, Tahira Y, Nagashima $H$, et al. Thalamic atrophy following cerebral infarction in the territory of the middle cerebral artery. Stroke 1991;22:615-8.

27 Yamaguchi T, Kurimoto M, Pappata S, et al. Effects of anterior corpus callosum section on cortical glucose utilization in baboons. Brain 1990;113:937-51.

28 Powers WJ. Cerebral hemodynamics in ischemic cerebrovascular disease. Ann Neurol 1991;29:231-40.

29 Kleiser B, Widder B. Course of carotid artery occlusions with impaired cerebrovascular reactivity. Stroke 1992;23: with impai $171-4$.

30 Yonas H, Smith HA, Durham SR, Pentheny SL, Johnson $\mathrm{DW}$. Increased stroke risk predicted by compromised cerebral blood flow reactivity. F Neurosurg 1993;79: 483-9.

31 Kuroda S, Kamiyama H, Abe $\mathrm{H}$, Houkin $\mathrm{K}$, Isobe $\mathbf{M}$, Mitsumori $\mathrm{K}$. Acetazolamide test in detecting reduced cerebral perfusion reserve and predicting long-term prognosis in patients with internal carotid artery occlusion. Neurosurgery 1993;32:912-8.

32 Powers WJ, Temple LW, Grubb RLJ. Influence of cerebral hemodynamics on stroke risk: one year follow-up of 30 medically treated patients. Ann Neurol 1989;25: 30 medica.

33 Hasegawa $Y$, Yamaguchi $T$, Tuchiya $T$, Minematsu $K$, Nishimura $T$. Sequential change of hemodynamic Nishimura $\mathrm{T}$. Sequential change of hemodynamic reserve in patients with major cerebral artery occ

34 Widder B, Kleiser B, Krapf H. Course of cerebrovascular reactivity in patients with carotid artery occlusions. Stroke 1994;25:1963-7.

35 Nariai T, Suzuki R, Hirakawa $K$, Maehara T, Ishii $K$, Senda $M$. Vascular reserve in chronic cerebral ischemia measured by acetazolamide challenge test: comparison with positron emission tomography. AfNR $\mathrm{Am} \mathcal{F}$ Neuroradiol 1995;16:563-70. 